\title{
Competitive Intelligence Information: A Key Business Success Factor
}

\author{
Cynthia A. Bulley ${ }^{1}$, Kofi F. Baku ${ }^{1} \&$ Michael M. Allan ${ }^{1}$ \\ ${ }^{1}$ Central Business School, Central University College, Ghana \\ Correspondence: Cynthia A. Bulley, Central Business School, Central University College, Accra, Ghana. Tel: \\ 233-24-416-0060. E-mail: ayorkorb@hotmail.com
}

$\begin{aligned} & \text { Received: December 31, } 2013 \\ & \text { Accepted: February 8, } 2014 \quad \text { Online Published: May 27, } 2014 \\ & \text { doi:10.5539/jms.v4n2p82 URL: http://dx.doi.org/10.5539/jms.v4n2p82 }\end{aligned}$

\begin{abstract}
Competitive intelligence (CI) plays a significant role in business management and practice. Management of companies have relied on competitive intelligence information to support decisions to give them an edge over their competitors. Companies use intelligence information to stay abreast and be in tune with the business environment. The purpose of this study is to understand the role of CI, the sophistication and intensity attached to it and examined the degree of knowledge of the processes in a firm. The exploratory study used triangulation and a survey to meet its objectives. Due to the sensitivity of the schedule, only 15 personnel were assigned to this task in the organization. The results indicate that XYZ Company is aware of the role and importance of CI but it is yet to fully utilize its potential. A major finding is that no single coherent CI process is being followed but rather a series of 'adhoc' measures are used. This implies that there is the need to develop systematic procedures for generating CI data and streamline the processes used in analyzing such information. The proposition is that though CI information is widely known and used, firms in Ghana do not follow precise tried and tested processes and there is the need to monitor the trend.
\end{abstract}

Keywords: competitive Intelligence, knowledge, external environment, information, business decision-making

\section{Introduction}

\subsection{The Essence of Competitive Intelligence Information}

In every industry, firms gather information from the external environment to understand and respond to that knowledge. Every company scoops for information about the industry and competitors to give them an edge. The process of gathering this information, filtering and putting it in a form that management can use the knowledge to their advantage is an important step which most firms do not pay much attention to. Most firms collect competitive intelligence information as part of a continuous process to help with planning and strategizing. This kind of information or knowledge help firms to focus, make decisions regarding their operations and functions. Kotler and Keller (2009), Etzel, Walker and Stanton (2004) and Fleisher (2001) defined competitive intelligence (CI) as a process that leads to information generation from competitors and the industrial environment for planning and decision making. Santos (2004) and Herring (1999) agree with this definition. But Herring (1999) emphasizes the essence of planning as the focus for generating CI information. Prior (2009) examines organizational intelligence and points to it being a "high level, processed, exploitable information". This definition examines and differentiates general information from CI information. CI information is 'privileged' information that should be processed to meet the requirements of management and decision makers. Business organizations and firms use different variations of processes and methods to generate $\mathrm{CI}$ information but the aim of such processes is to give firms some knowledge that would lead to a competitive advantage. It creates an enabling environment for organizations to have a competitive edge in a market. This is a major objective of firms who want to achieve competitive advantage over its competitors in the same industry. Viviers and Muller (2004) posit that South African companies have confirmed that CI influences and "positively enhances competitiveness". The study overall affirms the importance of CI as a business process in South Africa that goes beyond customer and industry analysis to the entire external environment. Cavalcanti (2005) also confirms the positive relationships between CI and company success. Therefore failure by companies to undertake intelligence gathering could lead to bias decision making. Lack of external environment information can degenerate to poor business performance. 
Wood (2001) and Takyi-Asiedu (1993) have lamented on the lack of tentative database for generating a list of all companies with some form of CI data in many developing economies. Some firms fall on research companies that are gaining grounds in developing countries. In Ghana where data compilation and storage is an issue and CI information a mirage, can one determine the role CI report plays in companies and how such information is used? The purpose of the study is to examine XYZ Company's CI system and the challenges it faces in compiling such data for processing. The specific objectives are:

to determine the role $\mathrm{CI}$ data collection plays in the company,

to identify the sophistication and intensity of CI data collection,

and determine the importance attached to CI information in XYZ Company.

\subsection{Significance of Competitive Intelligence in Firms}

$\mathrm{CI}$ has gained significant prominence in business management and practice. It adds value to a company's planning process and decision making. Porter and Millar (1991) alludes to information being a key to changing the tenets of competition. Viviers and Muller (2004) recognize CI as a strategic management process and Calof and Skinner (1999) perceive it as a systematic procedure for analyzing and disseminate information from the external environment. The Society for Competitive Intelligence Professionals (SCIP, 2008; 2011) define it as a managerial process that systematically mine for data that "can affect company plans, decisions and operations" for strategizing. For CI information to be relevant it should be part of the management system (Sharp, 2009; Gross, 2000). The linkage of CI with knowledge of the industry and strategic management is a critical process for organizations. And Porter's (1985) competitive strategy basically respond to this process through the environmental forces and how to fashion it to suit a company using intelligence information. Therefore CI information plays a significant role in business management. And there is the need to leverage all the strategic processes, decisions and operations with intelligence information to the advantage of a firm. A business will succeed or fail depending on whether management is well informed about the customers, suppliers and the environment within which they operate. Various studies have championed the CI studies but most of these have used large established companies that have well established systems in operation (Wright, Pickton, \& Callow, 2002; Lackman, Saban, \& Labasa, 2000; Prescott \& Smith, 1989). In Ghana, firms that embark on CI data generation and use it for business decisions do that in an informal manner with little or no budget or infrastructure to monitor the system, customers or external environment. Also some companies gather data on the industry and external environment but such information is of very little use to the firm if no action or response is generated from it. The extent or level to which companies are prepared to go to undertake competitive data generation determines it urgency and usage in the firm. Intelligence data collection is a continuous process but are companies constantly updating and monitoring competitors and the external environment? The focus on the role, level or extent of data generation and usage in the African context especially West Africa is limited. A notable study by Nasri (2010) in Tunisia explored the CI knowledge in companies and concluded that firms are "conscious" of its importance but are not using the appropriate measures to capture its full potential. In the case of Ghana, are firms aware of the relevance and advantages thereof of CI information to warrant its usage and prominence? This study is relevant because it sets the pace for other companies to re-examine $\mathrm{CI}$ activities and processes to take advantage of its potential in Ghana.

\subsection{Literature Review}

Intelligence activities as pointed out by Herring (2006), Leitl (2008) and Green (2004) is the centre of business decision making which should be part of management planning process. Santos (2004) and Fleisher (2001) have added that there is the need to define concisely the types of data required, the process of filtering, analyzing and turning the data into information. The methods, intensity and importance of such data and the use of that knowledge in the firm depend on the quality and extent or length to which the firm would go to get the data. The concept of intelligence information, knowledge and its implications for decision making are important business management concerns. Santos and Correia's (2010) studies on CI captures the essence of changing data and information on competitors and external environment into reliable and valuable material. Drucker (1998) linked $\mathrm{CI}$ to knowledge by differentiating and defining each scope. Competitor data that is 'endowed with relevance and purpose' is intelligence information, and exploiting and using the valuable information by management is the key to 'knowledge'. Knowledge is information acquired that can transform business operation. It is a major resource of the firm. Knowledge-based theory as employed in management, marketing and information system research by Penrose (1959), Conner (1991), Barney (1991), Thierauf (2001), Davenport and Prusak (1998) and others drive business decision making and information is the resource that feeds it. Researchers have argued that it is an off shoot of the resource-based view of the firm (Alavi \& Leidner, 2001; Grant, 1996) that goes a stage 
further but some critiques have challenged its tenet as a theory (Foss, 1996; Phelan \& Lewin, 2000). Information and knowledge operate in tandem. Intelligence information processing and knowledge play vital roles in competitive advantage (Porter, 1985). It is the knowledge acquired about competitors, customers and the entire external environment and how it is used to the benefit or advantage of the company that makes the difference.

\subsection{Competitive Intelligence Processing}

Competitive intelligence as a 'total process' have been discussed by Kahaner (1996), Lux and Peske (2002) and other researchers. Some researchers call it a cycle or system (Herring, 1999) whiles other see it as a process (Kahaner, 1996; Collins, 1997). The CI cycle or intelligence cycle is a "continuous seamless process" Figure 1 illustrates the process:

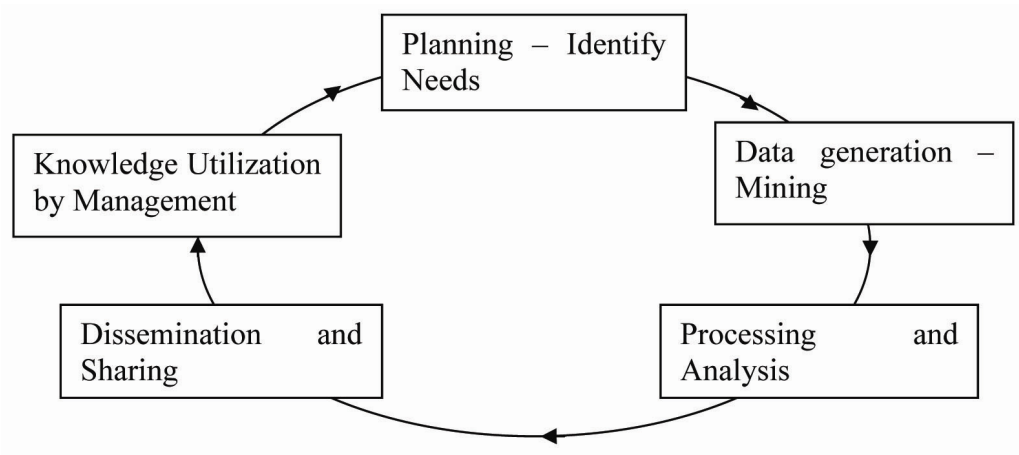

Figure 1. The competitive intelligence process (abridged version of Kahaner, 1997; Prescott \& Smith, 1989)

CI process basically start with data mining and conversion into 'intelligence' information which when given to management becomes knowledge that supports decision making. The planning in CI process identifies the intelligence needs of the firm, determines the focus area of that 'need' and plans subsequent activities (Herring, 1999; Fleisher, 2001; Rouach \& Santi, 2001; Santos, 2004). The techniques employed for generating the data with schedules of activities and processing tools must be laid out. Herring (1999), Wanderley (1999), and Lux and Peske (2002) have emphasized the need to define the sources to be used, "the volume, quantity and quality", access and ease of processing, the budget outlay available to be expended since it affects the outcome. The transformation of data to intelligence information is the crux of the process (Bose, 2008; Jin \& Bouthillier, 2006; Bergeron \& Hiller, 2002). Intelligence information results must be transmitted or disseminated timely to management. The value of information diminishes with time therefore timely execution of results of intelligence knowledge and subsequent feedback is important. Gilad and Gilad (1985) in their studies defined major steps of $\mathrm{CI}$ to include generating and mining for data from a large variety of sources. Fleisher (2008) emphasizes the variety of source to ensure adequate coverage of the entire business environment. CI process in the age of technology has seen great strides. The worldwide web and the search engines allow for basic data generation. Computer programmes like the SEO Profiler, a competitive intelligence tool enables firms to "spy on the back links of competitors' analytical reports and websites". CI digests like the Business Monitor and in the brewery industry the Global Brewer Analyser (www.rnrmarketresearch.com/global-brewer-analyser-report-2013-market-report.html) are essential reference guide. Many other sources abound making the process more of the budget available to dispense and experience of the personnel involved in such operations a priority. The processing should lead to decision making that brings about a change or an advantage to the firm.

\subsection{Knowledge Management and Usage}

Information is not valuable if the knowledge is not understood, not relevant, timely and cost effective and does not lead to better performance or competitive advantage. Every organization wants to achieve competitive advantage and knowledge of the external environment and its usage can lead to such difference. The ultimate is for management to formulate fact based actionable decisions from the knowledge acquired from CI activities. Kahaner (1997) posits that for firms to be in tune with the current speed and pace of business, management decisions should flow in a faster and more fluent manner. CI information should be a part of management processes to allow for proactive operations. Gross (2000) calls the CI information "a catalyst in the decision-making process". The implementation of CI in organizations seems simple but can be challenging. 
Management needs to understand the importance of $\mathrm{CI}$ and allocate enough resources or budget for operation of the intelligence unit. Failure to do that can lead to poor management and usage of this knowledge (Broome. 2001; Kahaner, 1997). The management of knowledge in most organizations is reflected in the decisions made by the firm and their performance in the industry. Further, organizations can safely anticipate changes by competitors, industry and the entire external environment to gear up for such "predictable surprises" (Bernhardt, 2005). Competitive Intelligence provides a foreknowledge that can put firms in a better position. The management and distribution of $\mathrm{CI}$ information in organizations determines the seriousness attached to such knowledge.

The understanding of CI practice is not significantly recognized in Ghanaian companies. Beyond sales records, market share, and innovative products implementation not much is done. Organizations profess to have research and development department which operates to generate customer and external environment information. But core intelligence reports that identifies opportunities and provide actionable information for management consumption seems to be given minor attention. Hinson (2005) has put forward various arguments that firms in Ghana "need to strategize to take advantage of the internet" if they should be better positioned. Some large organizations especially the multinational companies use formal methods for CI whilst informal methods are employed by the small and medium scale organizations. But all in all are there budgets allocated for CI and is it being used to the advantage of the organization? The exploratory review of XYZ Company should provide insight for a more in-depth analysis of CI role in organizations in Ghana.

\section{Methodology}

The exploratory research design was used to understand the current issues and activities relating to competitive intelligence and to address the research objectives. Data triangulation was employed at two different stages. First secondary data from different sources were reviewed to ascertain its relevance to the study and secondly, methodological procedures were examined to ensure validity and reliability. The survey design was used and it involved the collection and analysis of data, and finding out the answers concerning the present status of the subject. The anxiety over providing and sharing information about how XYZ Company monitor competitors was very sensitive therefore the convenience sampling method was adopted. The manager in charge of operations was consulted and the researchers ascertained which employees were most qualified to address the questions relating to competitive intelligence for the company. And to ensure free flow of information the researchers had to personally interact with the respondents to assure them of the confidentiality of the study.

\subsection{Sampling Procedures}

The determination of an appropriate sample size is crucial for the success of the study. The size of the sample has an important impact on the probability of errors and the precision of the estimate as well as other important factors associated with the research effort. Data for the study was collected from management level personnel in the research and sales department who were identified by the marketing manager. The sensitivity of the topic called for a small sample size since just a few people were scheduled to collect such data. The management personnel were then interviewed in order to provide a clear understanding of the topic understudy. Fifteen (15) questionnaires were sent to the manager in charge, however 12 responses were collected. This represents $80 \%$ response rate. Data gathered from this study were analysed qualitatively using descriptive and statistical analysis. Given the difficulty in getting access to all members of management, the study thus draw conclusions from the total population of the study based on the responses obtained.

\section{Results}

From the responses obtained majority of respondents were men (9) while the remaining were women (3). The age range indicates that $25 \%$ (3) were between 20 and 30years, another $66.67 \%$ (8) fell within the 31-40 years and $8.33 \%$ (1) indicated a range above 5lyears. The educational level of the respondents reveals that $66.67 \%(8)$ were first degree holders, $16.67 \%$ (2) have second degrees, $8.33 \%$ (1) were diploma holders and $8.33 \%$ (1) have professional qualifications. All the respondents have worked in the company for more than 3years $(58.33 \%$ (7), 4 to 7 years $-8.33 \%$ (1), 8 to 10 years $-25 \%$ (3) and more than 10 years- $8.34 \%$ (1).

All the respondents (100\%) confirmed that Research and Development of XYZ Company (XYZ) has been in operation as a department for gathering and analyzing information from their external environment and competitors. This is in order since the company must know and understand its business and its competitors' business to succeed (Porter, 1983, 1980; Global Intelligence Alliance, 2011, 2012). The study further revealed that XYZ has personnel appointed for competitive intelligence duties as majority (83.34\%) of the respondents answered 'Yes' to the question "are personnel appointed for competitive intelligence duties at XYZ?" Only $16.66 \%$ answered 'NO' to the same question. The study therefore shows that XYZ does not only attach great importance to competitive intelligence but also appoints responsible and skilled personnel to handle data 
generation. On the question of competitive intelligence data collection, all the respondents (100\%) affirmed that they are assigned and given areas to cover in such activities.

\subsection{Analysis of Responses Concerning Competitive Intelligence Process}

The respondents $(100 \%)$ revealed that XYZ Company extensively uses both formal and informal methods to generate intelligence data. The study also revealed that CI has its own budget and the company has a competitive intelligence strategy which is used in conducting competitive intelligence activities as indicated in table 1.

Table 1. Competitive intelligence budget and competitive intelligence strategy

\begin{tabular}{|c|c|c|c|c|c|c|}
\hline & Yes & & No & & Total & \\
\hline & Frequency & $\%$ & Frequency & $\%$ & Frequency & $\%$ \\
\hline $\begin{array}{l}\text { Does Competitive Intelligence have its own } \\
\text { budget? }\end{array}$ & 9 & 75 & 3 & 25 & 12 & 100 \\
\hline $\begin{array}{l}\text { Does your company have Competitive } \\
\text { Intelligence Strategy? }\end{array}$ & 11 & 91.67 & 1 & 8.33 & 12 & 100 \\
\hline $\begin{array}{l}\text { Does your company use this strategy in its } \\
\text { activities? }\end{array}$ & 8 & 66.67 & 4 & 33.33 & 12 & 100 \\
\hline
\end{tabular}

Source: Survey 2013.

The study also inquired from the respondents the sources XYZ uses to gather competitive data. The respondents had the opportunity of choosing more than one answer for this question. The results show that $50 \%$ of the respondents said data was collected from sampling customers, $33.33 \%$ also indicated research companies, $8.33 \%$ said government sources are used and another $8.33 \%$ said from other web based sources. The analysis implies that XYZ gathers competitive data from different sources which confirms Gilad and Gilad (1985) and Fleisher (2008) assertion in the literature review that a large variety of sources are used in generating and mining for data. The frequency of CI data generation from the respondent indicates varying results with $50 \%$ (6) indicating weekly, $41.67 \%$ (5) monthly and $8.33 \%$ (1) quarterly.

\subsection{The Use of Formal Procedures for Generating CI}

To determine if CI process operates smoothly and effectively in the firm, $75 \%(9)$ agreed that there is a formal process employed and 25\% (3) said there was no strict format. To determine if the formal processes used are in line with Kahaner (1997) and Prescott \& Smith (1989) CI process, 91.67\% (11) respondents stated a variation of the process is used with just $8.33 \%$ (1), the manager saying that the company adheres to the CI format. On the question of sophistication of methods used in data collection, no respondent mentioned any CI tool. All respondents (100\%) mentioned industry reports and formal company research, 75\% (9) said research companies are contacted to provide 'sensitive intelligence data and $83.33 \%$ (10) confirmed that informal methods like 'spying' on competitors are employed.

The question on whether analytical tools are employed in analysing data collected generated mixed results, with $41.67 \%$ (5) saying 'Yes' and . 58.33\% (7) saying 'No'. All the 5 respondents mentioned the computer as their analytical tool. No specific analytical programme was indicated. The 7 'No' response further indicated that analytical tools will enhance their reports. On the question of the frequency of CI reports to management, no specific time line was agreed on by all 12 respondents. The majority $33.33 \%$ (4) said there are no specific timeline but the urgency of the information generated determine the frequency of the reports. Further, $25 \%$ (3) said weekly, another $25 \%$ (3) said monthly and $16.67 \%$ (2) said quarterly reports are generated to management. There was no consensus here meaning that there are no laid down processes being followed by the company regarding information flow to management and CI reporting.

\subsection{The Sophistication and Intensity of CI Data Collection}

To find out the extent to which XYZ undertake competitive intelligence, $66.67 \%$ (8) of the respondents said the company undertake competitive intelligence 'to a greater extent' and $33.33 \%$ (4) ticked 'to some extent' with 0 for 'not to any extent'. The mean variance for the three items is 11 with a standard deviation of 3.32. The analysis revealed that $58.33 \%$ (7) of the respondents said the company attaches 'high intensity' to the generation of CI data, $33.33 \%$ (4) of the respondents said 'very high intensity' and $8.33 \%$ (1) indicated 'medium intensity'. The analyses also show a mean value of 2.4 and a standard deviation value of 2.73 . 
The focus of CI activities indicate that the most significant intelligence information was on 'customers' followed by competitors, brewery industry, distributors, marketing associations, internal sales and marketing employees and other respectively as in figure 2 . The standard deviation of the mean values is 0.806978 .

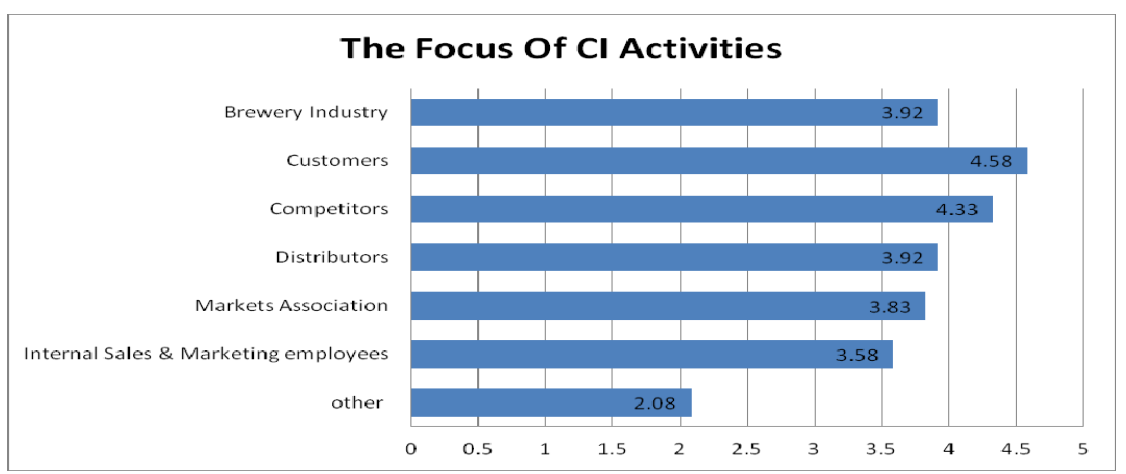

Figure 2. The focus of CI activities

The figures displayed at the end of the bars represent the mean/ average values from the responses $(1=$ not important/less focus to $5=$ extreme focus and importance - appendix 1 ).

\subsection{The Role of CI Data Collection in the Company}

All respondents (100\%) responded that CI data collection plays a significant role. But this question needs to be answered by top management therefore the manager in consultation with two others asserted that the firm's decisions $60 \%$ of time rely on $\mathrm{CI}$ information. From the analysis, $66.67 \%$ of the respondents agree that the company has a 'high' usage of competitive intelligence report as in figure 3.

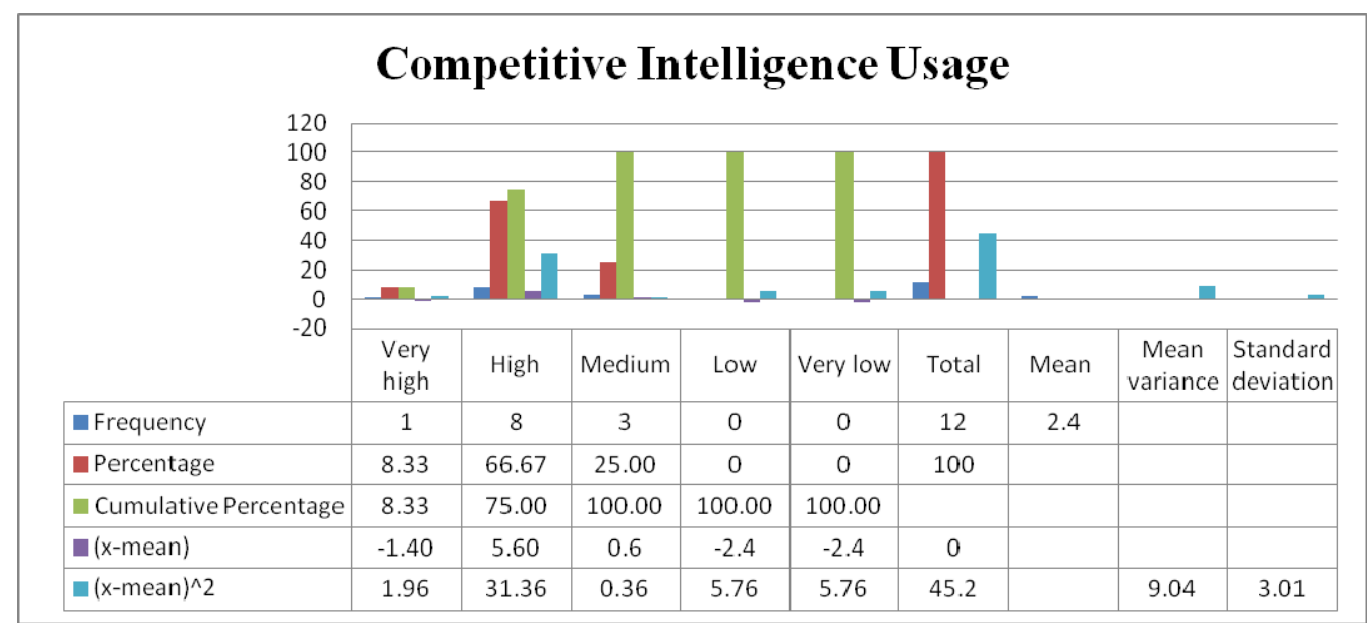

Figure 3. Level of competitive intelligent report usage

Source: Survey 2013.

The analysis for the main users of CI revealed that $75 \%$ (9) of the respondents stated management of the company, $16.67 \%$ (2) stated middle management and $8.33 \%$ (1) mentioned the sales department specifically. This confirms the literature that essentially management is the main users of CI.

\subsection{The Importance Attached to CI}

The importance of CI was sought from the respondents and $58.33 \%$ (7) agree that it is of 'very high importance' in the company, $16.67 \%$ (2) said it is of 'high importance' and $25 \%$ (3) said it of 'medium importance'. On the question of how CI information needs are identified in the company, 41.67\% (5) said management defines the CI needs and $58.33 \%$ (7) said the manager of the unit plans such activities. On the issues they envisage in sourcing 
for CI data, 50\% (6) said the future needs of the company in these competitive times are their major huddle, $33.33 \%$ (4) said identifying and locating relevant data and $16.67 \%$ (2) said lack of tools and laid down methods.

\section{Discussion and Conclusion}

The study sought to determine the role CI plays in company XYZ. From the findings it can be inferred that there is top management involvement in CI activities and personnel are appointed specifically for such activities. Though CI is considered as an essential tool for decision making, only $66.67 \%$ of the respondents agree that the company makes use of CI reports (figure 3). The study revealed that both formal and informal sources are used to generate CI data and there is no laid down format for processing and reporting such information. A new and robust data analysis and reporting system is needed to deal with the growing competition. Formal process or processes need to be implemented to build the culture of data generation, analysis and reporting. This will enable the firm to gather more accurate information. Also a formal process or instituted process for CI will enable the company to get the right information to react to the environment and market situation in a much faster way. The principal analyst should also be trained to use technological tools to make CI information relevant to the firm.

Furthermore, the study revealed that no sophisticated tools or programmes are used in data collection. Sampling customers (50\%), falling on research companies for information web based searches and government source are mainly used by the company. The intensity of CI data collection shows that the company knows the value of such activities and would need to formalise and build that kind of culture in the firm. All the respondents agree that $\mathrm{CI}$ is an important activity but the importance attached to it varies per the responses. The study suggests that a CI activity exists in the firm but it is not given prominence. More effort should be put into the intelligence process and structure for data flow and dissemination. Also the intelligence strategy should focus on definite objectives in terms of key information needs that would aid management decision making. CI is a key business success factor and should be distinctly defined and organised to benefit the organisation. This study increases the general knowledge of the practices of CI, its state and usage in firms in Ghana. It also emphasizes the need to examine deviations and practices to improve on the theoretical processes. The main limitation of the study is that it focuses on a particular case therefore cannot be considered as a representation of all companies in Ghana. Due to the exploratory nature of the research, it is expected that a more inclusive study of a number of companies in the same industry could be investigated in future. This will help to explore CI activities in Ghanaian firms and identify factors that would promote best practices. This research is needed to encourage other companies to take a second look at its CI activities.

\section{Acknowledgement}

Esther O. Duodu is acknowledged for the immense help with proof reading and other services.

\section{References}

Alavi, M., \& Leidner, D. (2001). Review: Knowledge Management and Knowledge Management Systems. MIS Quarterly, 25(1), 107-136. http://dx.doi.org/10.2307/3250961

Barney, J. (1991). Firm Resources and Sustained Competitive Advantage. Journal of Management, 17(1), 99-120. http://dx.doi.org/10.1177/014920639101700108

Bergeron, P., \& Hiller, A. C. (2002). Competitive Intelligence. Annual Review of Information Science \& Technology, 36(1), 353-390. http://dx.doi.org/10.1002/aris.1440360109

Bernhardt, D. C. (2003). Competitive Intelligence. Financial Times, Prentice Hall.

Ibid. (2005). Competitive Intelligence: The Lifeblood of Competitive Strategy. Alumni Newsletter, Graduate School of Management, University of Pretoria, South Africa.

Bose, R. (2008). Competitive Intelligence Process \& Tools for Inte/ligence Analysis. Industrial Management \& Data Systems, 108(4), 510-528. http://dx.doi.org/10.1108/02635570810868362

Broome, P. (2001). Making Competitive Intelligence Work for the Small Business. In C. S. Fleisher \& D. L. Blenkhorn (Eds.), Managing Frontiers in Competitive Intelligence: Lessons from the Trenches (pp. 200-209). New York: Wiley.

Calof, J. L., \& Skinner, B. (1999). Government's Role in Competitive Intelligence: What's Happening in Canada? Competitive Intelligence Magazine, 2(2), 20-30.

Cavalcanti, E. P. (2005). The relationship between Business Intelligence and Business Success. Journal of Competitive Intelligence and Management, 3(1), 6-15. 
Collins, R. J. (1997). Better Business Intelligence: How to Learn More about your Competitors. Gloucestershire: Management Books.

Conner. (1991). A Historical Comparison of Resource-Based Theory and Five schools of Thought within Industrial Organisation Economics: Do we have a new Theory of the firm? Journal of Management, 17(1), $121-154$.

Davenport, T. H., \& Prusak, L. (1998). Working Knowledge: How Organizations Manage What They Know. Boston: Harvard Business School Press.

Drucker, P. (1998). The Coming of the New Organisation. In Harvard Business Review on Knowledge Management (pp. 1-19). Harvard Business School. Boston, MA.

Etzel, M. J., Walker, B. J., \& Stanton, W. J. (2004). Introduction to Marketing (13th ed.). Hill/Irwin.

Fleisher, C. S. (2001). An Introduction to the Management and Practice of Competitive Intelligence. In C. S. Fleisher \& D. L. Blenkhorn (Eds.), Managing Frontiers in Competitive Intelligence: Lessons from the Trenches (pp. 3-18). Westport, CT: Quorum Books.

Ibid. (2008). Using Open Source Data in Developing Competitive and Marketing Intelligence. European Journal of Marketing, 42(7/8), 852-866. http://dx.doi.org/10.1108/03090560810877196

Foss, N. J. (1996). Knowledge-based Approaches to the Theory of the Firm: Some Critical Comments. Organizational Science, 7(5), 470-476. http://dx.doi.org/10.1287/orsc.7.5.470

Gilad, B., \& Gilad, T. (1985). A Systems Approach to Business Intelligence. Business Horizons, 28(4), 65-70. http://dx.doi.org/10.1016/0007-6813(85)90070-9

Global Intelligence Alliance. (2011). Market Intelligence in Global Organisations. Survey Findings in 2011. Retrieved from http://www.globalintelligence.com/insightsanalysis/market-intelligence-surveys/

Ibid. (2012). Market Intelligence in Global Organisations. Survey Findings in 2012. Retrieved from http://www.globalintelligence.com/insightsanalysis/market-intelligence-surveys/

Grant, R. M. (1996). Toward a Knowledge-Based Theory of the Firm. Strategic Management Journal, 17, $109-122$.

Green, C. E. (2004). De-Mystifying Distribution-Building a Distribution Strategy. TIG, Global/HSMAI Foundation.

Gross, M. (2000). Competitive Intelligence: A Librarian's Empirical Approach. Searcher, 8(8), 70-76.

Herring, J. P. (1999). Key Intelligence Topics: A Process to Identify and Define Intelligence Needs. Competitive Intelligence Review, $10(2), \quad 4-14$. http://dx.doi.org/10.1002/(SICI)1520-6386(199932)10:2<4::AID-CIR3>3.0.CO;2-C

Ibid. (2006). Developing Ethical Guidelines: Getting Started. In B. Hohhof \& D. Fehringer (Eds.), Competitive Intelligence Ethics: Navigating the Gray Zone (pp. 7-8). Washington, DC: Competitive Intelligence Foundation.

Hinson, R. (2005). Internet Adoption among Ghana's SME Non Traditional Exporters: Expectations, Realities and Barriers to Use. Africa Insight, 35(1), 20-27. http://dx.doi.org/10.4314/ai.v35i1.22421

Jin, T., \& Bouthollier, F. (2006). Understanding Information Transformation Process in the Context of Competitive Intelligence. Proceedings of the American Society for Information Science \& Technology, 43(1), 1-14. http://dx.doi.org/10.1002/meet.14504301303

Kahaner, L. (1996). Competitive Intelligence. Simon \& Schuster, New York.

Ibid. (1997). Competitive Intelligence: How to Gather, Analyze and Use Information to Move your Business to the Top. Simon \& Schuster, New York.

Kemper, H., \& Henning, B. (2006). Business Intelligence and Competitive Intelligence. Stuttgart, HMD 247.

Kotler, P., \& Keller, K. L. (2009). Marketing Management (13th ed.). Englewood Cliffs, New Jersey: Prentice Hall.

Lackman, C., Saban, H., \& Lanasa, J. (2000). Organising the Competitive Intelligence Function: A Benchmark $\begin{array}{lllll}\text { Study. } & \text { Competitive } & \text { Intelligence } & \text { Review, } & 11,\end{array}$ http://dx.doi.org/10.1002/(SICI)1520-6386(200031)11:1<17::AID-CIR4>3.0.CO;2-3

Leitl, M. (2008). Was it Competitive Intelligence? Harvard Business Manager, Heft 5. 
Lux, C., \& Peske, T. (2002). Competitive Intelligence and Industrial Espionage: Analysis, Practice, Strategy (1st ed.). Wiesbaden: Gabler.

Nasri, W. (2010). Competitive Intelligence in Tunisian Companies. Journal of Enterprise Information Management, 24(1), 53-67. http://dx.doi.org/10.1108/17410391111097429

Penrose, E. (1959). The theory of the Growth of the Firm. New York: Wiley.

Phelan, S. E., \& Lewin, P. (2000). Arriving at a Strategic Theory of the Firm. International Journal of Management Review, 2(4), 305-323. http://dx.doi.org/10.1111/1468-2370.00044

Porter, M. (1985). Competitive Advantage: Creating and Sustaining Superior Performance. New York: Free Press.

Porter, M., \& Millar, V. (1991). How Information Give You Competitive Advantage. Harvard Business Review.

Prescott, J., \& Smith, D. (1989). The Largest Survey of "leading - edge" Competitor Intelligence Managers. The Planning Review, 17(3), 6-13. http://dx.doi.org/10.1108/eb054253

Prior, V. (2009). Glossary of Terms Used in Competitive Intelligence and Knowledge Management. Retrieved from http://scip.cms-plus.com/files/Prior\%20Intelligence\%20Glossary\%2009Jan.pdf

Rouach, D., \& Santi, P. (2001). Competitive Intelligence Adds Value: Five Intelligence Attitudes. European Management Journal, 19(5), 552-559. http://dx.doi.org/10.1016/S0263-2373(01)00069-X

Santos, M., \& Correia, A. (2010). Competitive Intelligence as a source of Competitive Advantage: An Exploratory Study of the Portuguese Biotechnology Industry. Paper presented at the $11^{\text {th }}$ European Conference on Knowledge Management. Famalicäo, Portugal. September 2-3, 2010. Retrieved from http://run.unl.pt/bitstream/10362/4087/1/Santos_Correira_2010.pdf

Sharp, S. (2009). Competitive Intelligence Advantage: How to Minimize Risk, Avoid Surprises and Grow your Business in the Changing World. New Jersey: John Wiley \& Sons Inc.

Society of Competitive Intelligence Professionals. (2008). Society of competitive Intelligence Professionals. Retrieved from http://www.scip.org/content.cfm?itemnumber $=2226 \&$ navItemNumber $=2227$

Ibid. (SCIP, 2011). Retrieved from http://www.scip.org/content.cfm? itemnumber=2214\&navItemNumber=492

Takyi, A. (1993). Some Socio-cultural Factors retarding Entrepreneurial Activity iin Sub-Saharan Africa. Journal of Business Venturing, 8, 91-98. http://dx.doi.org/10.1016/0883-9026(93)90013-U

Thierauf, R. J. (2001). Effective Business Intelligence Systems. Quorum Books.

Viviers, W., \& Muller, M. L. (2004). Evolution of Competitive Intelligence in South Africa: Early 1980's to 2003. Journal of Competitive Intelligence and Management, 2(2), 53-67.

Wanderley, A. V. M. (1999). Um instrumento de macropolítica de informação: Concepção de um sistema deinteligência de negócios para gestão de investimentos de engenharia. Ciência da Informação, 28, 190-199. http://dx.doi.org/10.1590/S0100-19651999000200011

Wood, M. (2001). Marketing Information Systems in Tourism and Hospitality Small- and Medium sized Enterprise: A study of Internet for Market Intelligence. International Journal of Tourism Research, 3, 283-299. http://dx.doi.org/10.1002/jtr.315

Wright, M., Pickton, D. W., \& Callow, J. (2002). Competitive Intelligence in UK Firms: A Typology. Marketing Intelligence \& Planning, 20(6), 349-360. http://dx.doi.org/10.1108/02634500210445400

Note

Note 1. For the sake of confidentiality the name of the firm is referred to as XYZ Company. 


\section{Appendix A}

\section{The Focus of Competitive Intelligence}

\begin{tabular}{llllllll}
$1=$ & not important at all(less focus) & $5=$ extremely important (extreme focus) & & \\
\hline & 1 & 2 & 3 & 4 & 5 & total & Mean \\
\hline Brewery Industry & & & 4 & 5 & 3 & 12 & 3.92 \\
Customers & & 1 & 3 & 8 & 12 & 4.58 \\
Competitors & & 1 & 6 & 5 & 12 & 4.33 \\
Distributors & & 1 & 3 & 4 & 4 & 12 & 3.92 \\
Markets Association & & 1 & 3 & 5 & 3 & 12 & 3.83 \\
Internal Sales \& Marketing employees & & 1 & 5 & 4 & 2 & 12 & 3.58 \\
other & 2 & 6 & 4 & & & 12 & 2.17 \\
Standard Deviation & $\mathbf{0 . 8 0 6 9 7 8}$ & & & & & &
\end{tabular}

\section{Copyrights}

Copyright for this article is retained by the author(s), with first publication rights granted to the journal.

This is an open-access article distributed under the terms and conditions of the Creative Commons Attribution license (http://creativecommons.org/licenses/by/3.0/). 